\title{
A Comprehensive Investigation on Photocatalytic Properties of Macroporous Silicon
}

\author{
Chuan Lai ${ }^{1,2, *}$, Bin Xie ${ }^{2, *}$, Like Zou ${ }^{2}$, Xiao Ma ${ }^{2}$, Chenglong Deng ${ }^{2}$, Wan Gou ${ }^{1}$, Jianhai Hu ${ }^{1}$ \\ ${ }^{1}$ School of Chemistry and Chemical Engineering, Sichuan University of Arts and Science, Dazhou, \\ 635000, PR China \\ ${ }^{2}$ Key Laboratory of Green Catalysis of Higher Education Institutes of Sichuan, College of Chemistry \\ and Environmental Engineering, Institute of Functional Materials, Sichuan University of Science and \\ Engineering, Zigong, 643000, PR China \\ "E-mail: laichuanemail@163.com, xiebinsuse@126.com
}

doi: $10.20964 / 2017.07 .25$

Received: 3 April 2017 / Accepted: 6 May 2017 / Published: 12 June 2017

Here, the macroporous silicon (macro-pSi) was successfully prepared by electrochemical anodization silicon wafers in the etching solution of $1: 1 \mathrm{HF}(40 \%) / \mathrm{EtOH}(99.5 \%)(\mathrm{v} / \mathrm{v})$. Results show that macro-pSi with different thickness and porosity exhibit the different photocatalytic activity for methyl orange degradation, and the maximum value of decolorization efficiency is $66.62 \%$. Especially, the influence factors including photocatalysts dosage, current density, thermal treatment temperature, $\mathrm{pH}$ and recyclability for photocatalytic activity of macro-pSi as photocatalysts slice were systematically investigated. Furthermore, the decolorization kinetic equation is also presented in this work.

Keywords: Electrochemical anodization; Macroporous silicon; Photocatalytic activity.

\section{FULL TEXT}

(C) 2017 The Authors. Published by ESG (www.electrochemsci.org). This article is an open access article distributed under the terms and conditions of the Creative Commons Attribution license (http://creativecommons.org/licenses/by/4.0/). 